\title{
Thermal modelling for dynamic transformer rating in low carbon distribution network operation
}

\author{
J Yang, D Strickland \\ School of Engineering and Applied Science, Aston University, Birmingham, B4 7ET, U.K. Email: j.yang8@aston.ac.uk
}

\begin{abstract}
Keywords: Dynamic transformer rating, thermal modelling, low carbon network, distribution network operation.
\end{abstract}

\begin{abstract}
Dynamic asset rating is one of a number of techniques that could be used to facilitate low carbon electricity network operation. This paper focusses on distribution level transformer dynamic rating under this context. The models available for use with dynamic asset rating are discussed and compared using measured load and weather conditions from a trial Network area within Milton Keynes. The paper then uses the most appropriate model to investigate, through simulation, the potential gains in dynamic rating compared to static rating under two transformer cooling methods to understand the potential gain to the Network Operator.
\end{abstract}

\section{Introduction}

To enable Distribution Network Operators (DNOs) to develop new approaches to enforce the $11 \mathrm{kV}$ network with low carbon technologies, Ofgem [1] has released $£ 500 \mathrm{~m}$ of funding for DNOs to trial innovative techniques and share the learning with the rest of the industry. Project FALCON (Flexible Approaches to Low Carbon Optimised Networks [2]) is funded via this Ofgem initiative, and aims to facilitate the uptake of low carbon technologies by delivering faster and cheaper connections to the $11 \mathrm{kV}$ network by reducing traditional reinforcement requirements. The trial will provide learning on the use of real time data to inform network planning rather than traditional indicators such as total demand and engineering guidelines. The learning obtained throughout the project will be shared with other DNOs and the wider industry.

One of the techniques under study is that of dynamic asset rating (DAR). The FALCON trial covers five different asset types: primary ground mounted transformers $(33 \mathrm{kV} / 11 \mathrm{kV})$, secondary ground mounted transformers $(11 \mathrm{kV} / 415 \mathrm{~V})$, underground $33 \mathrm{kV}$ cables, underground $11 \mathrm{kV}$ cables and overhead $11 \mathrm{kV}$ conductors. This paper looks in detail at the thermal modelling for primary transformers at a key substation to help understand operational capacity and implications for operating life based on the assessment of transformer dynamic rating.

This paper is organised as follows: Dynamic transformer rating including process, modelling, transformer life, and operational experiences will be introduced in Section 2.
Section 3 will detail the models reviewed for hot-spot temperature calculation from standards and literatures. The case study with measured data is presented in Section 4 along with discussions and recommendations. Section 5 concludes the paper.

\section{Dynamic transformer rating}

Transformer life is seen primarily as a function of the state of the winding insulation, which degrades as a function of temperature. A high winding operating temperature results in quicker insulation degradation and therefore faster loss of transformer life. The highest temperature, known as the hotspot temperature, is located around the winding conductors but is not in any one fixed place and is a function of transformer design and cooling functionality, ambient air temperature, oil temperature, winding losses, aging effects amongst others. This makes the hot-spot temperature difficult to assess or measure with any degree of certainty.

Static load and cyclic load ratings are given by manufacturers, sometimes with different cooling mechanisms, to limit operating insulation temperatures (typically to less than $98^{\circ} \mathrm{C}$ or $110^{\circ} \mathrm{C}$ for a range of ambient temperatures up to $30^{\circ} \mathrm{C}$ ) to guarantee that an acceptable service life of at least 20 years can be achieved.

In reality, because transformers are typically rated to deal with worst case outage conditions and many transformers are located outdoors where the ambient temperature rarely reaches $30^{\circ} \mathrm{C}$, the transformers tend not to be operating close to their temperature limits resulting in a longer service life span. It is possible to take advantage of the conditions to rate the transformer dynamically based on hot-spot temperature rather than on a static load basis.

The formal definition of transformer dynamic rating/loading is "the maximum loading which the transformer may acceptably sustain under time-varying load and/or environmental conditions.” In most cases, dynamic rating will exceed the nameplate rating; however, in situations where environmental or transformer conditions are significantly less advantageous than the design assumptions, dynamic rating may be lower than the nameplate value. The elements forming the basis for dynamic loading include;

1) Changing ambient temperature

2) Insulating oil thermal time constant

3) The fact that thermal aging of insulation is a cumulative process 
Power transformers are generally the most expensive components in distribution networks. Cost savings and deferred replacement of transformers subject to loading constraints could be achieved if transformers can be operated beyond their nameplate ratings for certain periods [3]. For example, a transformer could be loaded above its nameplate rating when ambient temperature is low, without causing excessive overheating. Hence dynamic transformer rating was proposed and has been used for several purposes. The original idea is to cope with overloading, i.e. loading above the nameplate rating $[4,5]$, or highly fluctuating load profiles, such as for wind turbine transformers [6]. The main aim of a real time application is to take advantage of environmental impacts, e.g. low ambient temperatures to load a transformer above its nameplate rating without causing excessive overheating. This is particularly useful in meeting peak winter UK demand.

\subsection{Process overview}

Power transformers' condition monitoring is undertaken with sensors, online monitoring and intelligent tools, to maximise and safely utilise the potential benefits. Transformer lifetime is governed by the lifetime of its solid insulation. To comprehend the thermal effects that oil and winding temperatures have on the life of insulation, the hot-spot temperature is calculated based on ambient temperature and current measurement and measurement or calculation of oil temperature measurements. The dynamic rating process can be performed in real time or offline planning [3]:

When the data given is a 24-h profile (of loading condition and ambient temperature) it could be used only as an offline planning tool: given the ambient temperature profile and the present condition of the unit, how high can a given 24-h load profile be increased without exceeding any of the specified limits? The output is a continuum of ratings given for the 24$\mathrm{h}$ period. This is normally used in international guides. When latest recording of preload is available, the analysis could be a real time process [3]: given the present ambient environment, condition, and load of the unit, what is the maximum load that can be carried for various periods of time into the future without exceeding any of the specified limits?

For each time interval, equations based on selected models are employed to calculate interested parameters such as topoil temperature rise and then hot-spot temperatures, loss of life etc. This process is iterated until all the time intervals have been gone through for the specified load profile of a typical day. A general dynamic rating process can be performed in real time or offline planning, which is shown in Figure 1.

A particular step of "State Estimation" is shown in the process. This depends on operational data of oil temperature measurement if sensors are available to measure the top-oil temperature and cooling system status. Although this may produce unrealistic jumps in updated rated temperatures due to the difference in measured and calculated value, it is a good way to guarantee a better evaluation result. The influence of ambient conditions (rain, solar radiation, and wind) and the load profiles may also be superimposed if realtime measurements are provided. Moreover, the thermal response could be validated by using statistical analysis of the load pattern, through evaluation of the oil/winding time constants, and other relevant parameters which will be discussed further in the algorithm.

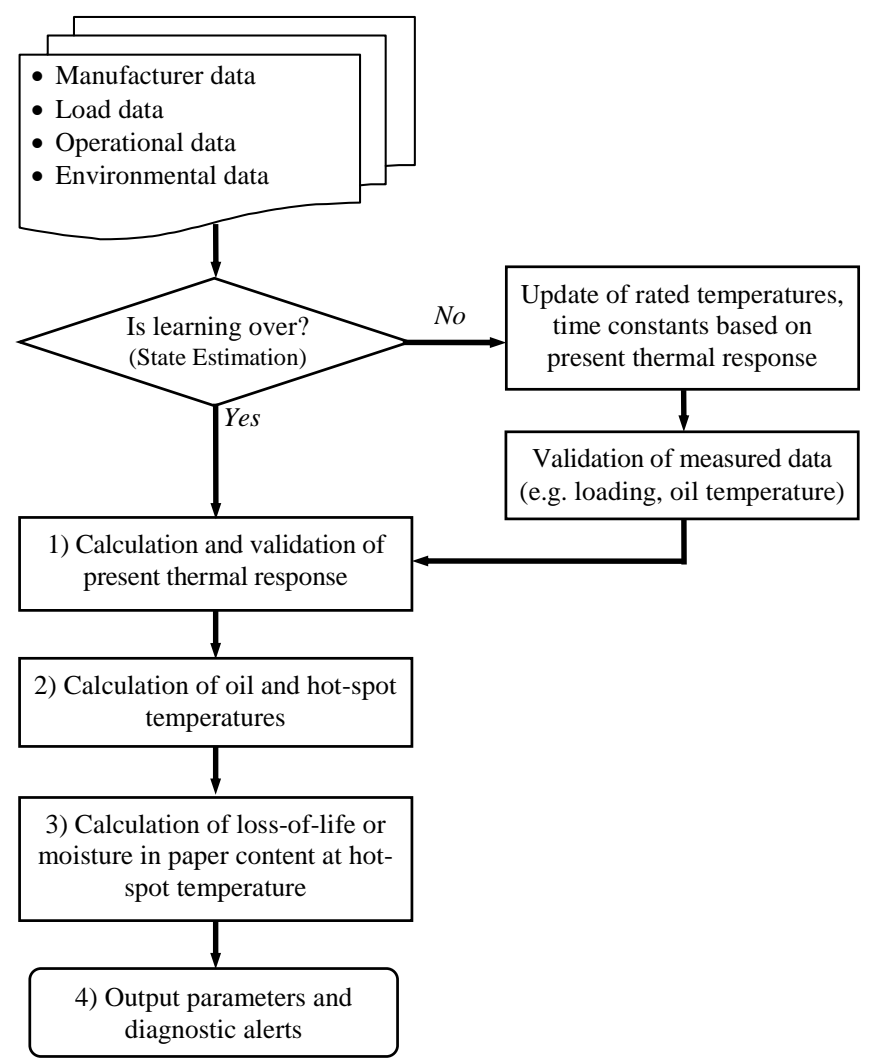

Figure 1: Overview of transformer dynamic rating process.

\subsection{Thermal modelling}

Existing dynamic thermal modelling for transformers mostly consider constant ambient temperature along with pre-set test loading with characteristics of: increasing load steps followed by a decreasing load step or vice versa; each step has to be long enough (2-5 hours) for the temperature to obtain steady state. This is not fit-for-purpose for currently available "realtime" monitored distribution network which could have varying loading data in periods of 3-30 minutes. Wind and solar effects are also seldom considered for thermal modelling. A generalised or specific model for distribution transformers is required aside from the too generalised model of standards.

The industrial standards modelled transformer thermal responses by estimating the hot-spot temperature of windings. This is generically represented by top-oil temperature rise and hot-spot temperature rise on top of the ambient temperature:

$$
T_{h s}=T_{o}+\Delta T_{h s}=T_{a}+\Delta T_{o}+\Delta T_{h s}
$$


where $T$ denotes temperatures, $\Delta T$ denotes temperature rises subscript $o$ refers to top-oil values, subscript $h s$ refers to hotspot values, and $a$ refers to ambient values.

\subsection{Transformer life}

Transformer lifetime is governed by the lifetime of its solid insulation. Equations allow estimating consumption of transformer life based on the hot-spot temperature models. To calculate loss-of-life, an aging accelerating factor has to be considered. This is called relative aging rate, to represent the deterioration rate of different parts, with non-uniform temperature distribution. Different formulae are used for different insulation paper: thermally upgraded paper or not. For example, the relative aging rate $(V)$ for thermallyupgraded paper insulation is [7]:

$$
V=e^{\left(\frac{15000}{110+237}-\frac{15000}{T_{h s}+273}\right)}
$$

The loss of life over a period from $t_{1}$ to $t_{2}$ is approximated by the summation of relative aging rate multiplied by the time step [7]:

$$
L=\int_{t_{1}}^{t_{2}} V d t \approx \sum_{n=1}^{N} V_{n} \times t_{n}
$$

\subsection{Operational experience}

One implementation of transformer DAR in distribution networks in New Zealand is reported in 2012 which is the most updated application of this technique [8]. However, this is simply implementing the IEC model without model justification or algorithm comparison.

\section{Transformer thermal modelling}

The practice of transformer dynamic rating is to comprehend the thermal effects that oil and winding temperatures have on the life of insulation. Although direct measurement methods have already been proposed [9], they can only be applied to newly built units, for which the manufacturer installed technically advanced measuring facilities (for instance sensors with fibre-optic cables). Therefore, the highest temperature existed inside the windings (so called hot-spot temperature) as opposed to the oil temperature may only be computed for most applications. This means oil temperature measurement may not be required. The winding temperature indicators are routinely fitted, providing measurement of a manufacturers' proxy for hottest spot.

A number of equations exist, which estimate consumption of transformer life based on the hot-spot temperature models. The international standards [7, 10] or other guides for mineral-oil-immersed transformer loading, offer algorithms for computations the top-oil and hot-spot temperatures and the loss of the paper insulation life. The models considered for this study are mainly from the IEC standard [7] and EA technology report [11]. IEEE model is also mentioned in the model comparison section.

1) Exponential model (IEC 60076-7)

2) Differential model (IEC 60076-7)

3) Exponential model (IEEE C57.91, IEC 354)

4) Differential model considering wind and solar effects (EA Technology)

Table 1 shows a summary of the transformer thermal models looked at for this project.

\begin{tabular}{|l|l|l|l|l|l|l|}
\hline Standard & Load & Model & $\begin{array}{l}\text { Time } \\
\text { constant }\end{array}$ & $\begin{array}{l}\text { Cooling } \\
\text { mode }\end{array}$ & $\begin{array}{l}\text { Wind } \\
\text { /solar }\end{array}$ & Year \\
\hline IEC 354 & Step & $\begin{array}{l}\text { Expon- } \\
\text { ential }\end{array}$ & Fixed & $\sqrt{ }$ & $\mathrm{x}$ & 1991 \\
\hline $\begin{array}{l}\text { IEEE } \\
\text { C57.91 }\end{array}$ & Step & $\begin{array}{l}\text { Expon- } \\
\text { ential }\end{array}$ & Variable & $\sqrt{ }$ & $\mathrm{x}$ & 2011 \\
\hline $\begin{array}{l}\text { IEC } \\
60076-7\end{array}$ & Step & $\begin{array}{l}\text { Multi- } \\
\text { expon- } \\
\text { ential }\end{array}$ & Fixed & $\sqrt{ }$ & $\mathrm{x}$ & 2005 \\
\hline $\begin{array}{l}\text { IEC } \\
\text { 60076-7 }\end{array}$ & Dynamic & $\begin{array}{l}\text { Differ- } \\
\text { ential }\end{array}$ & Fixed & $\sqrt{ }$ & $\mathrm{x}$ & 2005 \\
\hline $\begin{array}{l}\text { EA } \\
\text { Tech }\end{array}$ & Dynamic & $\begin{array}{l}\text { Differ- } \\
\text { ential }\end{array}$ & N/A & $\sqrt{ }$ & $\sqrt{ } / \mathrm{x}$ & 2011 \\
\hline
\end{tabular}

Table 1: Summary of the transformer thermal models in review.

Expressions are shown as follows to appreciate the mathematical characteristics in terms of exponential or differential models:

\section{A. IEEE C57.91-2011}

This model uses exponential functions (for both the top-oil and winding hot-spot temperatures) for transients between initial and ultimate temperatures.

$$
\begin{gathered}
\Delta T_{o}=\left(\Delta T_{o, u}-\Delta T_{o, i}\right)\left(1-e^{-\frac{t}{\tau_{o}}}\right)+\Delta T_{o, i} \\
\Delta T_{h s}=\left(\Delta T_{h s, u}-\Delta T_{h s, i}\right)\left(1-e^{-\frac{t}{\tau_{w}}}\right)+\Delta T_{h s, i}
\end{gathered}
$$

where $\tau_{\mathrm{o}}$ and $\tau_{w}$ are the oil and winding time constants.

\section{B. IEC 60076-7: 2005}

In this standard [7], section 8.2.3, the time-domain differential equations given are:

$$
\begin{gathered}
T_{h s}=T_{o}+\Delta T_{h s} \\
\Delta T_{h s}=\Delta T_{h s 1}-\Delta T_{h s 2} \\
k_{11} \tau_{o} \frac{d T_{o}}{d t}+T_{o}=T_{a}+\Delta T_{o r}\left(\frac{1+K^{2} R}{1+R}\right)^{x} \\
k_{22} \tau_{w} \frac{d \Delta T_{h s 1}}{d t}+\Delta T_{h s 1}=k_{21} K^{y} \Delta T_{o r}
\end{gathered}
$$




$$
\frac{\tau_{o}}{k_{22}} \frac{d \Delta T_{h s 2}}{d t}+\Delta T_{h s 2}=\left(k_{21}-1\right) K^{y} \Delta T_{\text {or }}
$$

In standard form to put in MATLAB:

$$
\begin{gathered}
\frac{d T_{o}}{d t}=-\frac{1}{k_{11} \tau_{o}} T_{o}+\frac{1}{k_{11} \tau_{o}} T_{a}+\frac{1}{k_{11} \tau_{o}} \Delta T_{o r}\left(\frac{1+K^{2} R}{1+R}\right)^{x} \\
\frac{d \Delta T_{h s 1}}{d t}=-\frac{1}{k_{22} \tau_{w}} \Delta T_{h s 1}+\frac{1}{k_{22} \tau_{w}} k_{21} K^{y} \Delta T_{o r} \\
\frac{d \Delta T_{h s 2}}{d t}=-\frac{k_{22}}{\tau_{o}} \Delta T_{h s 2}+\frac{k_{22}}{\tau_{o}}\left(k_{21}-1\right) K^{y} \Delta T_{o r}
\end{gathered}
$$

where $K$ is the load factor (load current/rated current), subscript $r$ refers to rated values.

These differential equations are approximated by using difference models assuming that calculation for each time step is linear. Therefore the ultimate temperature values may different from the exponential models, even if previous step result is used as initial value for the next step calculation. The IEC multi-exponential model is omitted here. However, the idea is the same as exponential model to represent transients between calculated values.

The factors used within the formula have been determined empirically and the values used within the calculations in this paper are given in Table 2.

\begin{tabular}{|l|l|l|}
\hline & ONAN & OFAF \\
\hline Oil exponent $x$ & 0.8 & 1.0 \\
\hline Winding exponent $y$ & 1.3 & 1.3 \\
\hline Loss ratio $R$ & 10.75 & 10.75 \\
\hline Hot-spot factor $H$ & 1.3 & 1.3 \\
\hline Oil time constant $\tau_{o}$ & 210 & 90 \\
\hline Winding time constant $\tau_{w}$ & 10 & 7 \\
\hline $\begin{array}{l}\text { Hot-spot to top-oil (in tank) gradient } \\
\text { at rated current } \Delta T_{h r}\end{array}$ & 26 & 22 \\
\hline $\begin{array}{l}\text { Top-oil (in tank) temperature rise } \\
\Delta T_{\text {or }}\end{array}$ & 52 & 56 \\
\hline$k_{11}$ & 0.5 & 1.0 \\
\hline$k_{21}$ & 2.0 & 1.3 \\
\hline$k_{22}$ & 2.0 & 1.0 \\
\hline
\end{tabular}

Table 2: IEC thermal model parameters.

\section{EA Technology-2011}

This is also a differential model [11]. However, the physical representations are eliminated such as oil and winding thermal responses. Relevant factors are considered by constant parameters.

$$
\begin{aligned}
\frac{\partial T_{h s}}{\partial t}= & \frac{1}{A}\left[I-(B+C) \times \operatorname{Cool} \times\left(T_{h s}-T_{a}\right)\right. \\
& \left.-D \times v_{\text {wind }}^{2} \times\left(T_{h s}-T_{a}\right)\right]
\end{aligned}
$$

where $I$ is the load current, Cool is the cooling mode, wind speed $v_{\text {wind }}$ is considered and fitted by coefficient $D$. A similar term representing solar irradiation, as item could be added with factor $E$ as

$$
\begin{aligned}
\frac{\partial T_{h s}}{\partial t}= & \frac{1}{A}\left[I-(B+C) \times \operatorname{Cool} \times\left(T_{h s}-T_{a}\right)\right. \\
& \left.-D \times v_{\text {wind }}^{2} \times\left(T_{h s}-T_{a}\right)+E \times P_{\text {solar }} \times\left(T_{h s}-T_{a}\right)\right]
\end{aligned}
$$

A curve-fitting method is required to find appropriate parameters $(A-E)$ for the model based on field operational data.

\section{Case study}

To compare the aforementioned models, the FALCON trial asset data is employed as a case study to identify the most appropriate model.

\subsection{Data}

\section{A. Asset data}

A pair of primary transformers at Marlborough Street substation in the Milton Keynes area has been analysed. They are $33 \mathrm{kV} / 11 \mathrm{kV}-12 / 19 / 24 \mathrm{MVA}$ transformers, with cooling type ONAN/OFAF (ONAN - oil natural air natural and OFAF - oil forced air forced). The rating of the transformer is dependent on the cooling adopted. From the test certificate, the rated current is 209.9A primary, 602.5A secondary for ONAN cooling and 332.4A primary and 953.9A secondary OFAF cooling. No-load loss: $6610 \mathrm{~W}$ (at $0.8 \mathrm{pf}$ regulation), full-load loss: $71052 \mathrm{~W}$ on tap 9, 68537W on tap 1 and 77045W on tap 17.

\section{B. Other data}

The models have been tested with annual load data from 2012. Half hour time slot load data supplied by the DNO has been used. Load factor is calculated by the of load current to rated secondary current (602.5A). Corresponding ambient temperature data from the MET office has been used.

\subsection{Model implementation}

MATLAB (R2011a) is used to implement the algorithms of various models. For exponential models, special handling of calculated steady-state values and transient values is required due to time constants and data availability, as detailed in the next section. All the differential equations are solved by using difference numerical methods, assuming the time step is small enough for the response during each step to be treated as linear.

\subsection{Results and discussions}

The performance of different models, and effects of load factor, cooling mode and ambient temperature, wind speed are simulated by the coded models in MATLAB. Each factor is detailed as follows:

\section{A. Model Comparison}

Simulation results over the 327 days are shown in Figure 2. 


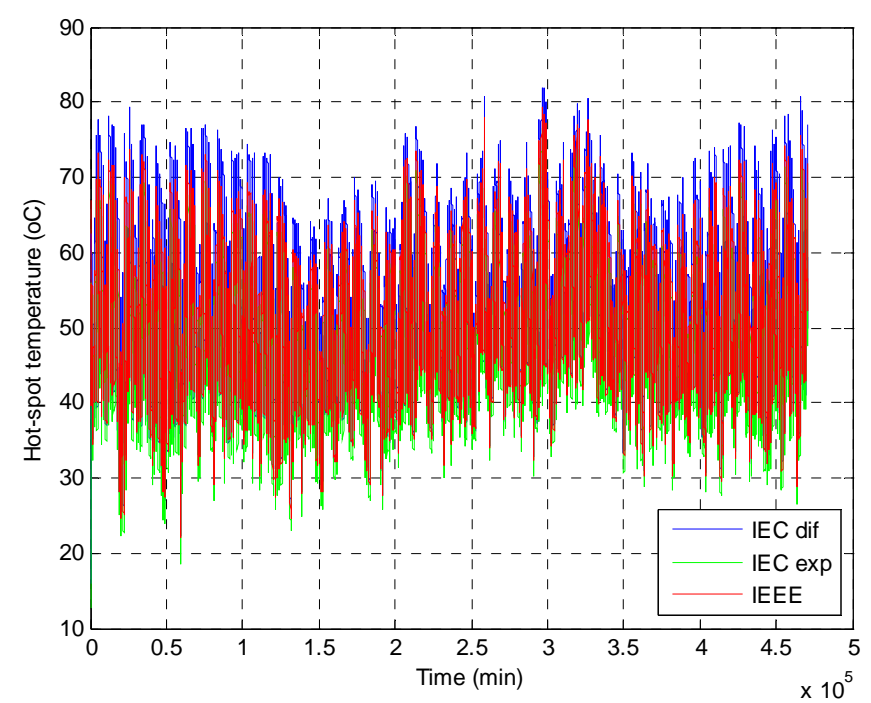

Figure 2: Hot-spot temperature calculation with different models (IEEE vs. IEC).

In terms of maximum temperature values of hot-spot, the IEC exponential and differential models are in accordance with each other. However, the fluctuations of the exponential model are higher than the differential model. The peak temperature results show differences in the region of up to $10^{\circ} \mathrm{C}$ difference between models. This is in accordance with previous experimental results of oil temperature measurement and model calculation [12]. All the modelled hot-spot temperatures are well below the recommended peak hot-spot temperature in this circuit.

Although during winter/spring period the IEEE model has slightly higher results, the hot-spot temperature range and expected mean values for IEC are higher. The limited range of oil temperature is the cause of less fluctuation compared with IEEE. This can be adjusted if measured oil temperatures are available.

It is worth noting that for the exponential function based models (IEEE and IEC exponential), the simulation period is less than the oil time constant (in range of 150-200 minutes). This means the model results have not reached a steady state value within the modelling time period and results in higher fluctuation of results. On the other hand, for the differential function based models (IEC differential and EA technology model), the simulation period is less than the winding time constant (in range of 7-10 minutes). This means that within the 30 minute time slot the data will have reached steady state and this results in lower overall fluctuations. With more realtime data, it is expected that IEC differential model should give the most conservative results (highest mean temperatures) among the three models. In the EA technology report for the STP projects [11], a variable that represents the temperature change due to wind speed found from multiplying the square of wind speed $(\mathrm{m} / \mathrm{s})$ with a co-efficient is used. The difficulty of using this model is to decide appropriate parameters. To achieve this, lots of trial data is required along with curve-fitting/parameter-training algorithms. It is not currently planned to collect data in sufficient quantity from the FALCON project to enable the EA technology model to be fully implemented and compared, but outline indications show good correlation.

Tap-position was also considered as a factor influencing the resultant temperatures. However, the change of transformer losses under different taps is negligible compared to other factors. For instance, results show that the temperature drop at Tap No.1 is only $0.1-0.2^{\circ} \mathrm{C}$ compared to the normal position of Tap No. 9; while the temperature increase at Tap No. 17 about $0.1-0.25^{\circ} \mathrm{C}$.

\section{B. Implications for Network Operators}

Standards typically state that $110^{\circ} \mathrm{C}$ is the unit life winding temperature for thermally upgraded paper. This means that the winding temperature can reach $110^{\circ} \mathrm{C}$ without there being any noticeable additional loss of life. Using this information in conjunction with the IEC differential model, the maximum load current in conjunction with the weather conditions for a time step period has been used to determine the maximum loading on the transformer compared to the static rating for ONAN and OFAF cooling applied constantly. Figure 3 shows two days in February that have extreme temperatures. The maximum and minimum dynamic rating is then shown on Figures 4 and 5 as a line marking the range of the rating compared to the static rating for that month. Figures 4 and 5 show the scope of dynamic rating for the two cooling types for each month.

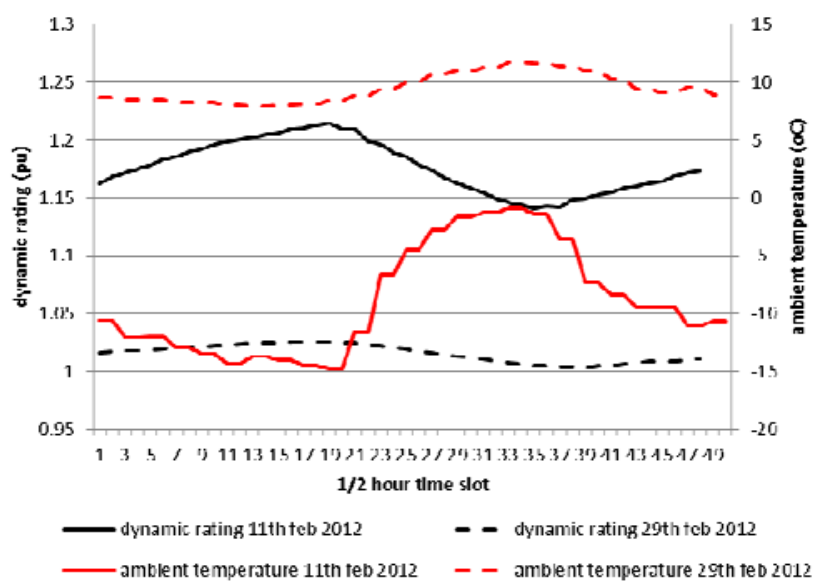

Figure 3: Example of dynamic rating over a 24hr period for unit loss-of-life operation $\left(110^{\circ} \mathrm{C}\right.$ limit) with OFAF cooling.

Investigating the effect of continuous loading at 19MVA compared to a dynamic rating (with temperature hotspot limit set to $110^{\circ} \mathrm{C}$ ) shows that there is scope to run at up to $20 \%$ higher continuous current in the winter months. However, under high ambient conditions this dynamic rating may also reduce in the summer months. Peak load in 2012 occurred in February, and modelled dynamic ratings indicated a good margin due to low temperatures. Due to the thermal capacity of the system an increased dynamic overload on the transformer could be applied for several hours. Based on modelling of continuous load and looking closer at the data, on a month by month data (both with and without forced 
cooling gives an idea as to where gains in dynamic rating may be obtained. January to May and October to December offer gains in dynamic rating on some if not all of the days of the month. As the ambient temperature increases there is a much more marked effect on the shape of the modelled temperature curve from March to October to mimic the ambient temperature variation. For these spring/autumn periods, winding temperature indicators are routinely fitted, providing measurement of a manufacturer's proxy for hottest spot this theoretical analysis suggests a slight advantage at morning load pick up, but no advantage at peak load period. However, the curves from this analysis for June to September suggest that no additional increase in dynamic rating is likely even at night and in fact there may even be a drop in the static rating required. Validating the model against additional test data which will be collected as part of the FALCON trial will allow the model accuracy to be tested and the full range of dynamic ratings to be calculated.

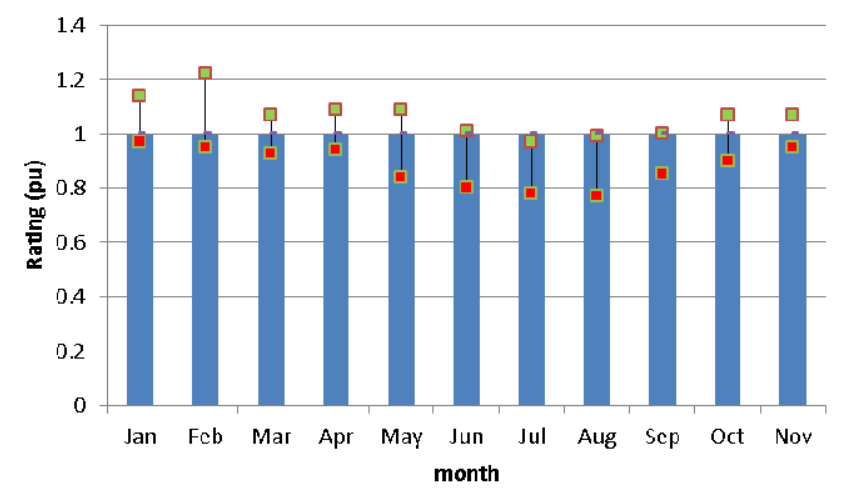

Figure 4: Dynamic rating limits under ONAN cooling for unit lossof-life operation $\left(110^{\circ} \mathrm{C}\right.$ limit).

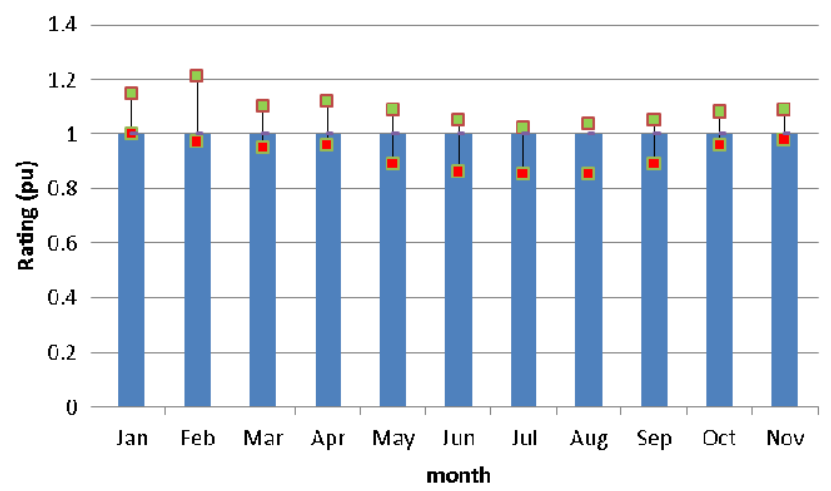

Figure 5: Dynamic rating limits under OFAF cooling for unit lossof-life operation $\left(110^{\circ} \mathrm{C}\right.$ limit).

\section{Conclusion}

This paper presents a theoretical analysis of the different published mathematical models with particular emphasis on recorded loading profiles, and implementation issues, such as, the calculation time step and long/short-term loading responses. Limited pre-trials Falcon Network operational data is used to illustrate potential future case study findings, and shows how different models perform in a real-life type situation using MET office recorded environmental data, and
DNO recorded load profiles. As a result of this work, the IEC differential model is recommended as the most appropriate model for UK distribution power network applications. A backward calculation for potential transformer capacity at a specified hot-spot temperature was implemented that illustrated how gains or reductions in asset capacity over a full year's period could be assessed. Results with validated model and trial monitored winding temperature data will be reported in planned future papers.

\section{Acknowledgements}

The authors would like to thank Western Power Distribution plc. for their support to realise the production of this paper.

\section{References}

[1] Ofgem. Low Carbon Networks Fund, https://www.ofgem.gov.uk/electricity/distributionnetworks/network-innovation/low-carbon-networks-fund

[2] Western Power Distribution. FALCON, http://westernpowerinnovation.co.uk/Falcon.aspx

[3] M. F. Lachman, P. J. Griffin, W. Walter, A. Wilson. "Realtime dynamic loading and thermal diagnostic of power transformers,", IEEE Transactions on Power Delivery, volume 18, no. 1, pp. 142-148, (2003).

[3] B. D. Lahoti, D. E. Flowers. "Evaluation of transformer loading above nameplate rating”, IEEE Transactions on Power Apparatus and Systems, volume PAS-100, no. 4, pp. 19891998, (1981).

[4] J. A. Jardini, J. L. P. Brittes, L. C. Magrini, M. A. Bini, J. Yasuoka. "Power transformer temperature evaluation for overloading conditions", IEEE Transactions on Power Delivery, volume 20, no. 1, pp. 179-184, (2005).

[5] D. Susa, M. Lehtonen, H. Nordman. "Dynamic thermal modelling of power transformers", IEEE Transactions on Power Delivery, volume 20, no. 1, pp. 197-204, (2005).

[6] J. McCarthy. "Analysis of transformer ratings in a wind farm environment”, Master degree thesis, Dublin Institute of Technology, (2010).

[7] International Electrotechnical Commission (IEC). "Power transformers - Part 7: Loading guide for oil-immersed power transformers,” IEC 60076-7, pp. 1-110, (2005).

[8] T. S. Jalal, N. Rashid, B. van Vliet. "Implementation of dynamic transformer rating in a distribution network,” IEEE International Conference on Power System Technology (POWERCON), Auckland, New Zealand, 30 Oct. - 2 Nov. (2012).

[9] Working Group 09 of Study Committee 12. "Direct measurement of the hot-spot temperature of transformers," CIGRE document, Ref. 096, pp. 17-21, (1995).

[10] Transformers Committee of the IEEE Power \& Energy Society. "IEEE Guide for Loading Mineral-Oil-Immersed Transformers and Step-Voltage Regulators,” IEEE Std C57.912011 (Revision of IEEE Std C57.91-1995), pp. 1-123, (2012).

[11] EA Technology. "Transformer Dynamic Ratings,” STP report, project S5196_4, (2011).

[12] R Vilaithong, S Tenbohlen, T Stirl. "Investigation of different top oil temperature models for on-line monitoring system of power transformer," IEEE International Conference on Condition Monitoring and Diagnosis (CMD), Changwon, Korea, 2-5 Apr. (2006). 